\title{
Bioinspired Nanofiber Scaffold for Differentiating Bone Marrow-Derived Neural Stem Cells to Oligodendrocyte-Like Cells: Design, Fabrication, and Characterization [Corrigendum]
}

Rasti Boroojeni F, Mashayekhan S, Abbaszadeh HA, Ansarizadeh M, Khoramgah MS, Rahimi Movaghar V. Int J Nanomedicine. 2020;15:3903-3920.

Page 3908, left column, Isolation and Characterization of BMSCs section, the text "Afterward, PBS was used to wash the fixed cells twice and the cells were incubated at $4^{\circ} \mathrm{C}$ with antibodies specific for the following antigens: CD34, CD45, CD90, CD44, Nestin, NF68, GFAP for 30 mins" should read "Afterward, PBS was used to wash the fixed cells twice and the cells were incubated at $4^{\circ} \mathrm{C}$ with antibodies specific for the following antigens: CD45, CD29, CD73, CD105, Nestin, NF68, GFAP for 30 mins".

Page 3909, right column, the section heading "Static Analysis" should read "Statistical Analysis".
A

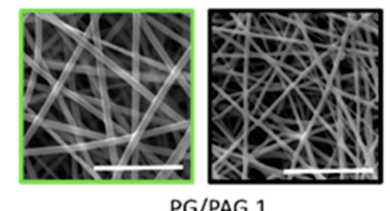

PG/PAG 1

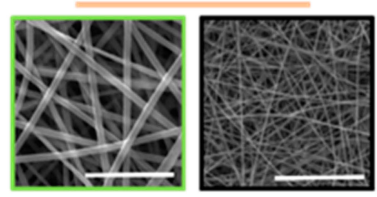

PG/PAG 2

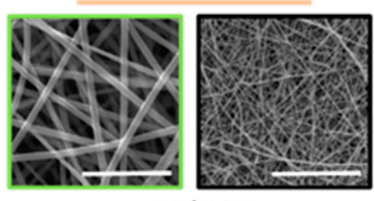

PG/PAG 3

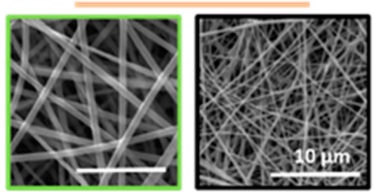

B

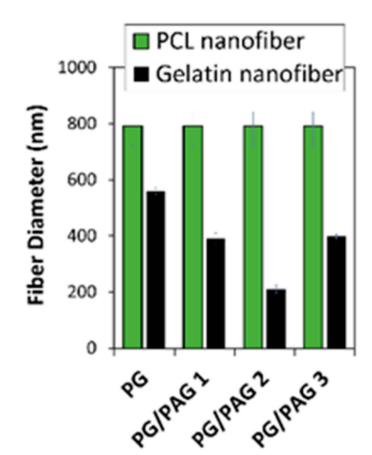

$E$

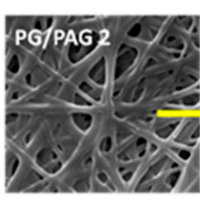

$\mathbf{0}$ day
Figure 2 on page 3910, the scale bar in part E shows " $2 \mu \mathrm{M}$ " it should read " $10 \mu \mathrm{m}$ ". The text "(the condition and concentration of PCL nanofibers was exactly the same for all four groups, thus the same SEM image was used to show the PCL nanofibers for all groups)" has also been added to the figure caption.

The correct Figure 2 is shown below.

Page 3911, BMSCs Characterization section, the text "In this analysis, CD44, CD90, and CD 106 markers as mesenchymal stem cell markers and CD45 as hematopoietic stem cells marker were used" should read "In this analysis, CD29, CD73, and CD 105 markers as mesenchymal stem cell markers and CD45 as hematopoietic stem cells marker were used".

C
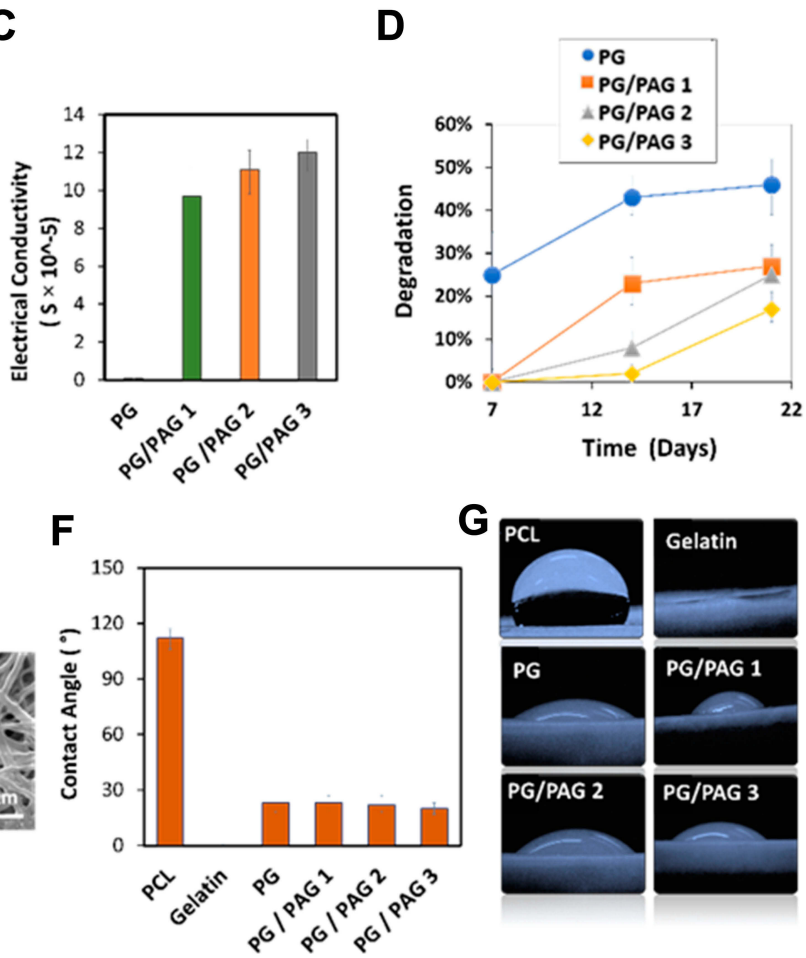

$\mathbf{G}_{\mathrm{PCL}}$

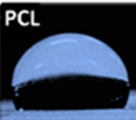

PG

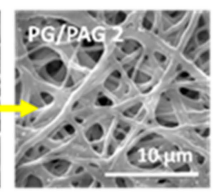

21 days after cell culturing

Figure 2 Fabrication and analysis of conductive PAG-loaded gelatin nanofiber scaffold. (A) SEM graphs of PCL/gelatin nanofibers, left images show PCL nanofibers and the right images show gelatin nanofibers (since the condition and concentration of PCL nanofibers was exactly the same for all four groups, thus the same SEM image was used to show the PCL nanofibers for all groups), (B) nanofiber diameter, (C) electrical conductivity, (D) degradation rate, (E) SEM images of PG/PAG 2 at day 0 and day 2 I after cell culturing, $(\mathbf{F})$ contact angle measurement of scaffolds, $(\mathbf{G})$ the condition of water droplet on different scaffolds. 
A
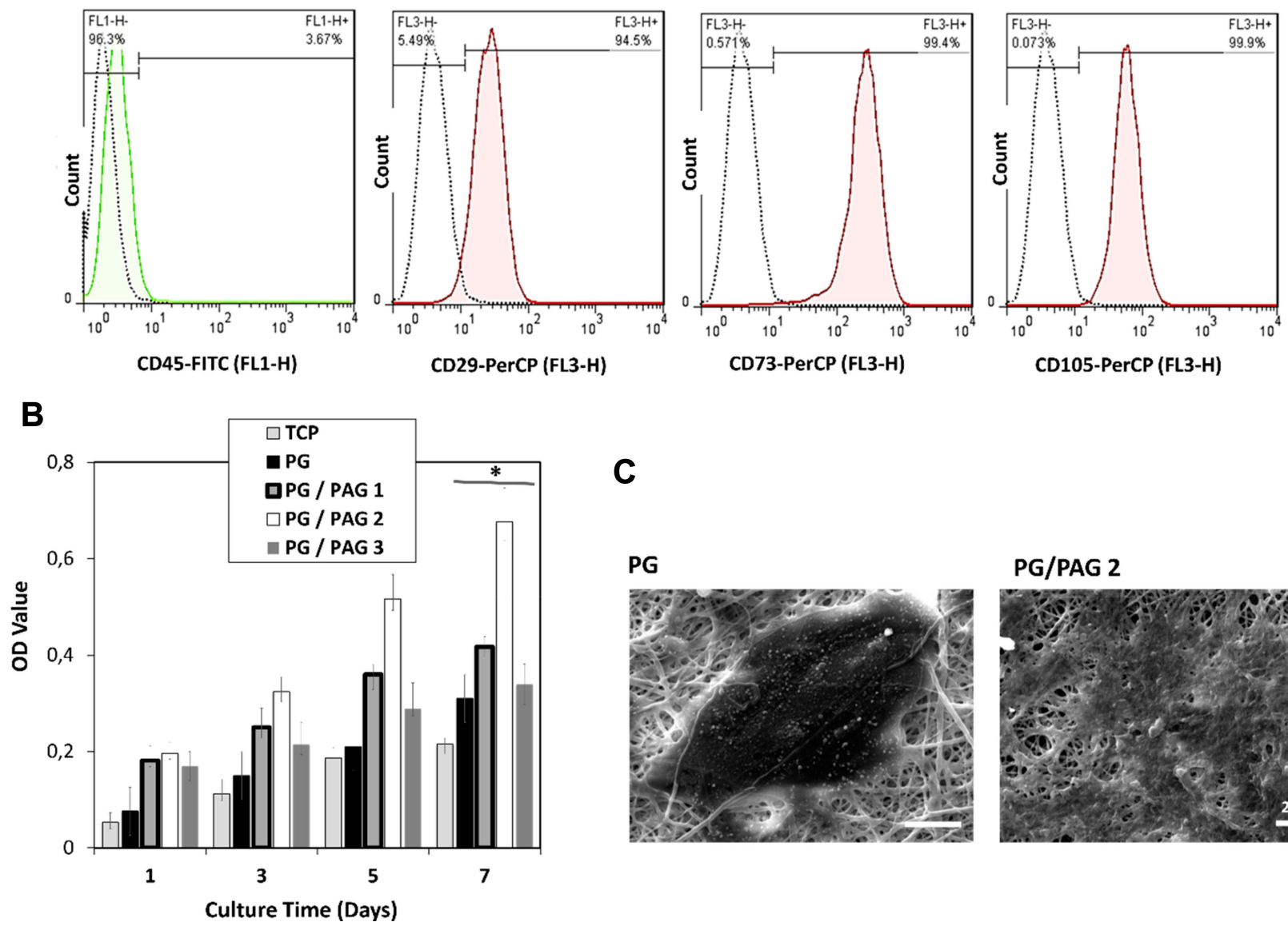

C

PG

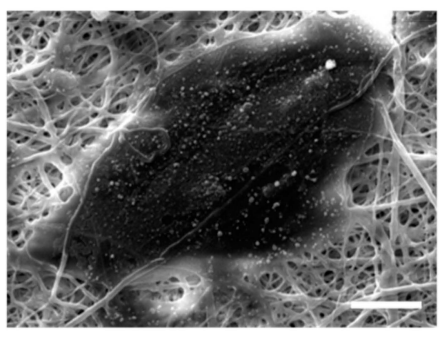

PG/PAG 2

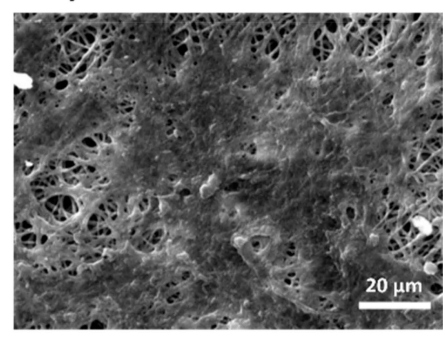

Figure 3 Characterization of BMSCs and cell viability analysis of BMSCs on scaffold. (A) The flow cytometry analysis of CD45, CD29, CD73 and CDI05 for BMSCs, (B) cell viability on PCL/gelatin scaffolds containing various amount of PAG, *Indicates significant difference of $P<0.05$, (C) cell spreading on two different scaffold.

Figure 3 on page 3912, the scale bar in part C shows "20 $\mu \mathrm{M}$ " it should read " $20 \mu \mathrm{m}$ ".

The correct Figure 3 is shown above.

Figure 5 on page 3914, the scale bar in part A shows "10 $\mu \mathrm{M}$ " it should read " $10 \mu \mathrm{m}$ ". The text "(the condition and concentration of gelatin nanofibers was exactly the same for PG/PAG 2, PG/PAG 2/1\% NP, PG/PAG 2/2\% NP, and PG/PAG $2 / 3 \%$ NP $\%$, thus the same SEM image was used to show the gelatin nanofibers for all groups)" has also been added to the figure caption.
The correct Figure 5 is shown below.

The authors have advised there is an error in the caption of Figure 7 on page 3916. The text "scale bar $=20 \mu \mathrm{M}$ " should read "scale bar $=20 \mu \mathrm{m}$ ".

Figure 8 on page 3917, the scale bars in part B shows " $\mu \mathrm{M}$ " they should read " $\mu \mathrm{m}$ ".

The correct Figure 8 is shown below.

The authors apologize for these errors. 
A

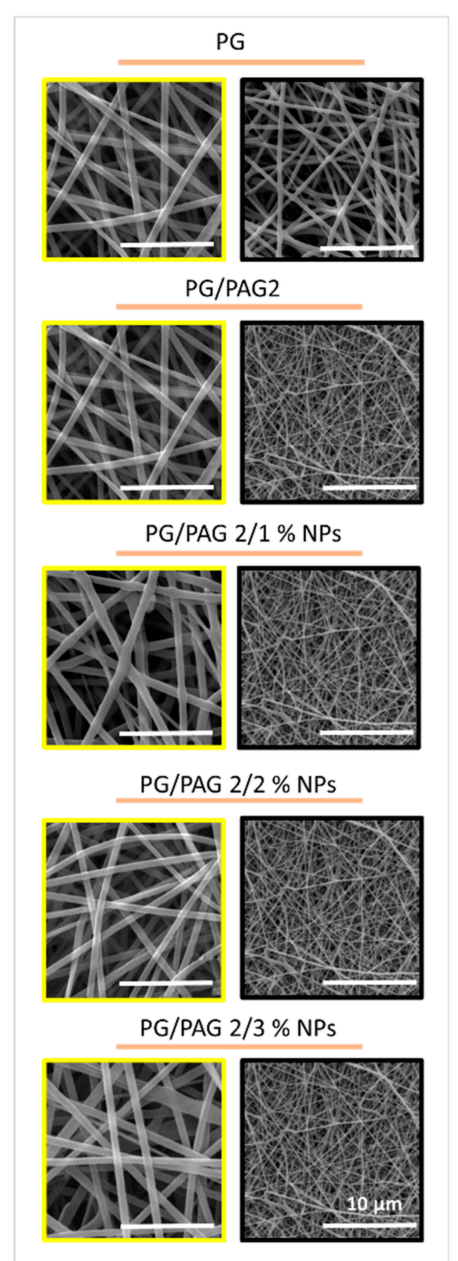

B

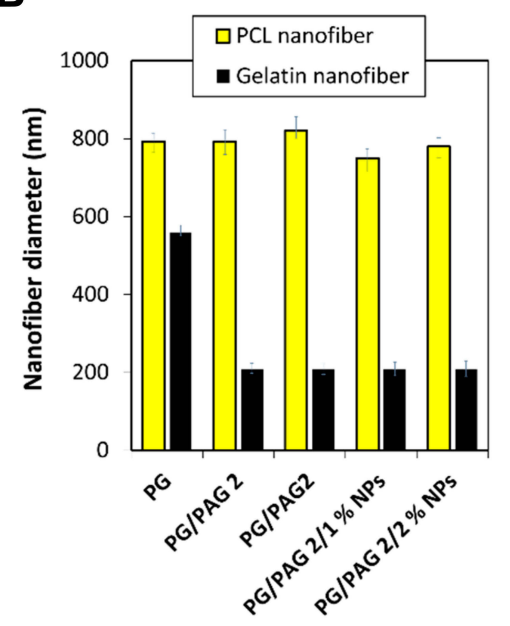

C

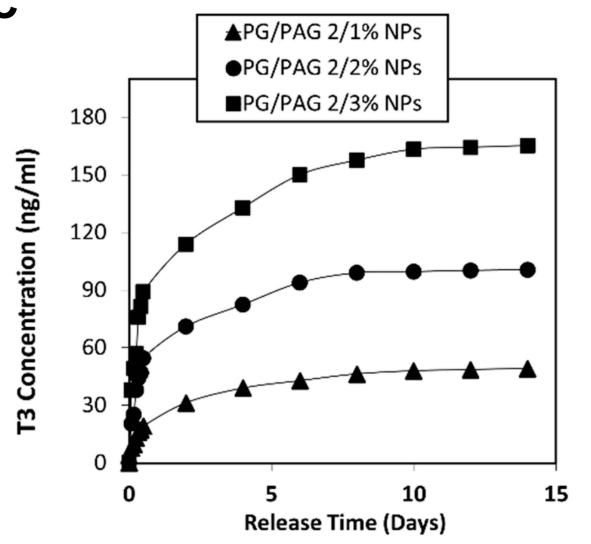

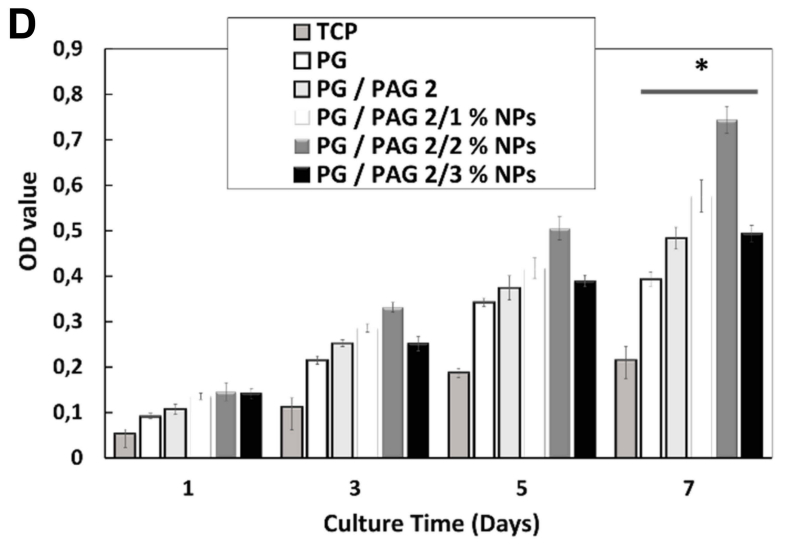

Figure 5 Characterization of T3-loaded nanofiber scaffold. (A) SEM graphs of PCL/gelatin nanofibers, left images show PCL nanofibers containing T3-loaded chitosan NPs and the right images show gelatin nanofibers containing PAG nanoparticles (since the condition and concentration of gelatin nanofibers was exactly the same for PG/PAG 2, PG/PAG 2/I\% NP, PG/PAG 2/2\% NP, and PG/PAG 2/3\% NP \%, thus the same SEM image was used to show the gelatin nanofibers for all groups), (B) nanofiber diameter, (C) release profile of T3 from PCL/gelatin scaffolds containing various amount of T3-loaded chitosan NPs, (D) BMSCs viability on PG, PG/PAG 2, PG/PAG 2//\% NP, PG/PAG 2/ $2 \% \mathrm{NP}$, and PG/PAG $2 / 3 \% \mathrm{NP} \%$; *ndicates significant difference of $p<0.05$. 


\section{A}
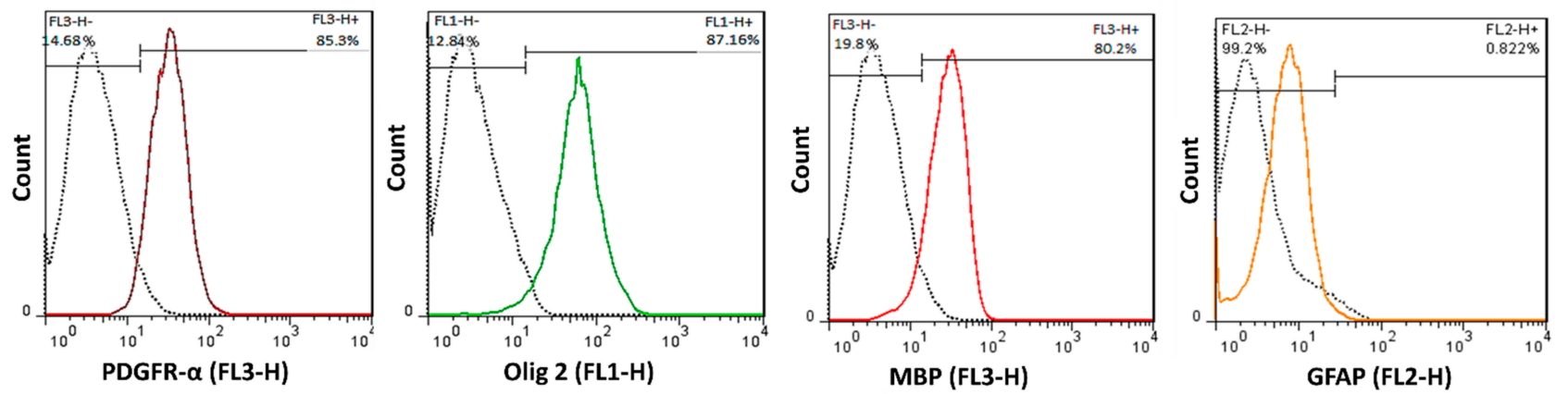

\section{B}

Differentiated OLC Day\#1

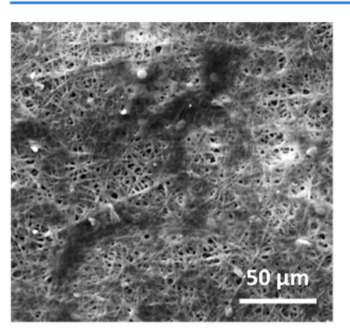

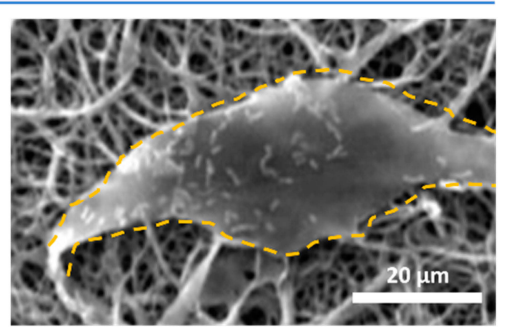

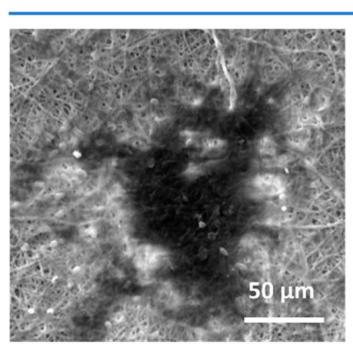

Differentiated OLC Day\#14

Figure 8 Characterization of the differentiation of NSCs to OLCs on PG/PAG 2/2\% NP scaffold. (A) Flow cytometry analysis of the expression of PDGFR-a, Olig 2, MBP, and GFAP markers in differentiated OLCs, (B) SEM images of morphological changes of differentiated OLC cultured on PG/PAG $2 / 2 \%$ NP scaffold at day I and day I4.

\section{Publish your work in this journal}

The International Journal of Nanomedicine is an international, peerreviewed journal focusing on the application of nanotechnology in diagnostics, therapeutics, and drug delivery systems throughout the biomedical field. This journal is indexed on PubMed Central, MedLine, CAS, SciSearch ${ }^{\mathbb{B}}$, Current Contents ${ }^{\mathbb{B}} /$ Clinical Medicine,
Journal Citation Reports/Science Edition, EMBase, Scopus and the Elsevier Bibliographic databases. The manuscript management system is completely online and includes a very quick and fair peer-review system, which is all easy to use. Visit http://www.dovepress.com/ testimonials.php to read real quotes from published authors. 